See discussions, stats, and author profiles for this publication at: https://www.researchgate.net/publication/308276599

\title{
Cytological Criteria for Predicting the Luminal Phenotype of Breast Carcinoma
}

Article in Acta cytologica · September 2016

DOl: $10.1159 / 000448835$

CITATION

1

4 authors, including:

Rafael Bispo Paschoalini

São Paulo State University

5 PUBLICATIONS 2 CitATIONS

SEE PROFILE
READS

66

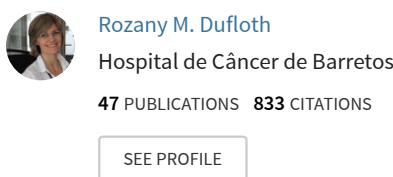

Some of the authors of this publication are also working on these related projects:

Exame ctitopatológico em mulheres gestantes e não-gestantes: fatores associados View project

Serviço de Anatomia Patologica HU/UFSC View project 


\title{
Cytological Criteria for Predicting the Luminal Phenotype of Breast Carcinoma
}

\author{
Rafael Bispo Paschoalini ${ }^{a}$ Rozany Mucha Dufloth ${ }^{a, b}$ \\ Francisco Alves Moraes Neto ${ }^{c}$ Fernando C. Schmitt ${ }^{d}$ \\ ${ }^{a}$ Department of Pathology, Faculty of Medicine, São Paulo State University, Botucatu, b Barretos Cancer Hospital, \\ Pio XII Foundation, Barretos, and 'Laboratory of Pathology, Hospital Amaral Carvalho de Jaú, Jaú, Brazil; \\ ${ }^{\mathrm{d}}$ Department of Pathology and Medicine, Laboratoire National de Santé 1, Dudelange, Luxembourg
}

\section{Key Words}

Breast carcinoma - Cytological criteria - Cytopathology, breast · Fine needle aspiration cytology · Luminal

phenotype $\cdot$ Molecular classification

\begin{abstract}
Background: Specific cytological criteria for the luminal phenotype of breast carcinoma, despite it being the most common and having a better prognosis as well as targeted therapies under study, remain to be established. Using fineneedle aspiration cytology (FNAC), we aimed to identify the luminal phenotype through the evaluation of cytological criteria recognized in routine practice. Methods: We correlated 169 FNACs of breast carcinomas with their tissue specimens, classified into phenotypes by immunohistochemistry (applying tissue microarray technology) as luminal A, luminal B, HER2 overexpression, and triple negative. All FNAC samples were blindly reviewed according to cellularity, cell cohesion, necrosis, nucleoli, and nuclear atypia. Fisher's exact test was used to test associations between the cytological criteria and phenotypes. Results: The following phenotypes were obtained - luminal A: 107 (63.3\%), luminal B: 39 (23.1\%),
\end{abstract}

HER2 overexpression: 8 (4.7\%), and triple negative: 15 (8.9\%). The luminal phenotype showed mild/moderate cellularity (40.4\%) $(\mathrm{OR}=7.12,95 \% \mathrm{Cl}: 1.61-31.52)$, inconspicuous, present nucleoli (55.5\%) (OR $=8.31,95 \% \mathrm{Cl}: 2.36-29.19)$, and $\mathrm{mild} /$ moderate nuclear atypia $(44.5 \%)(\mathrm{OR}=8.42,95 \% \mathrm{Cl}$ : 1.90-37.25). Conclusion: The criteria that might indicate the luminal phenotype of breast carcinoma in FNAC were mild/ moderate cellularity, inconspicuous, present, and nonprominent nucleoli, and mild/moderate nuclear atypia.

(c) 2016 S. Karger AG, Base

\section{Introduction}

Breast carcinoma is widely known as a heterogeneous disease requiring separation of clinically relevant groups for treatment, surveillance, prevention of disease progression, and research $[1,2]$. Genetic studies have confirmed a previous morphological impression of heterogeneity and continue to improve the understanding of the biology of breast carcinoma. Besides big data provided by multicenter molecular studies and international epidemiological reports, efforts to translate this high-cost knowledge

\section{KARGER}

E-Mail karger@karger.com www.karger.com/acy
(C) 2016 S. Karger AG, Basel

0001-5547/16/0000-0000\$39.50/0
Correspondence to: Dr. Rafael Bispo Paschoalini Department of Pathology, Faculty of Medicine São Paulo State University, Distrito de Rubião Júnior, s/n Botucatu, SP 18618970 (Brazil)

E-Mail rbpaschoalini@alunos.fmb.unesp.br 
into clinical practice still face some challenges, especially concerning early diagnosis [3-6]. From a pathologist's perspective, morphological and immunohistochemical correlates - as provided by surrogate classification of molecular phenotypes - can be useful tools in the attempt to reach this goal [7-10].

Since its description by Martin and Ellis in 1930 [11], fine-needle aspiration cytology (FNAC) has been a widely used and accepted method for obtaining samples for cytological diagnosis in various organs and is a primary procedure for the assessment of breast lumps. FNAC is a fast, low-cost technique, with great diagnostic accuracy and with minimum risks to patients [12-15]. Well-fixed smears along with the cell blocks obtained are optimal adjuncts to perform ancillary techniques, such as immunocytochemistry and molecular tests [16-19]. Moreover, FNAC has a great intrinsic potential (concerning cytomorphology) to supply additional information to the diagnosis of breast carcinoma for each case [17-19], which has been used in attempt to predict molecular phenotypes of breast carcinomas [20].

Gene expression profiling techniques are not the current standard in clinical practice, but, for nearly a decade, hormone receptor (HR) testing and determination of the human epidermal factor neu receptor (HER2) status has been a routine part of treatment planning $[6,21,22]$. In the meantime, the number of commercially offered multigene prognostic/prediction assays employed in clinical decision making has increased $[2,9]$. There are two HR+ breast carcinomas (luminal A and B) and two HR- carcinomas (HER2+ and basal like). The molecular subtypes can be approximated by HR/HER2 status and Ki-67 index; i.e. luminal A (HR+/HER2-/low Ki-67 index), luminal B (HR+/HER2 \pm /high Ki-67 index), HER2 overexpression (HR-/HER2+), and triple negative (HR-/ HER2-) [1, 5, 7-10]. The basal phenotype is characterized by immunoreactivity for basal or myoepithelial cell markers by applying, in general, a combination of highmolecular-weight cytokeratins (CK5/CK6, CK14, and CK17) and epidermal growth factor receptors [23, 24].

Cytomorphologically, the basal phenotype has been investigated and described due to its relation to hereditary breast carcinoma [20]. However, the luminal phenotype, despite being the most common and having better prognosis as well as targeted therapies under study, has not yet been characterized using specific cytological criteria. Using FNAC, we aimed to identify the luminal phenotype of breast carcinoma through the evaluation of cytological criteria recognized in routine practice, once it is relevant for guiding treatment and predicting survival.
Table 1. Sources and dilutions of primary antibodies used in the immunohistochemical study

\begin{tabular}{lllll}
\hline Antibody & Clone & Dilution & Manufacturer & Retrieval \\
\hline E-cadherin & NCH-38 & $1: 100$ & Dako & Citrate pH6 \\
ER & SP1 & $1: 100$ & Spring & Citrate pH6 \\
PR & SP42 & $1: 200$ & Spring & Citrate pH6 \\
HER2 & SP3 & $1: 200$ & Spring & Citrate pH6 \\
Ki-67 & MIB-1 & $1: 200$ & Dako & EDTA \\
\hline
\end{tabular}

\section{Materials and Methods}

\section{Samples}

This study was based on a review of preoperative FNAC samples obtained before the histological diagnosis of ductal or lobular invasive breast carcinoma of biopsy and mastectomy specimens from 237 patients treated at the Oncology Hospital Amaral Carvalho (Jaú, Brazil) from 2000 to 2009. FNAC samples were previously stained with Giemsa (direct air-drying fixation), hematoxylin and eosin (HE), and Papanicolaou (PAP) stains (immediate fixation in $95 \%$ alcohol). The initial result of cytological analysis in the laboratory of origin, based on the NIH Consensus Development Conference, was named the initial cytology result. FNAC samples were analyzed using a multiheaded microscope (Olympus ${ }^{\circledR}$ BX50). All slides were analyzed by two senior pathologists (F.A.M.N. and R.M.D.) blinded to the histological data on each case. The complete evaluation of cytological criteria and correlation with histological data was performed on 169 cases. Lack of cytological material, absence of histological data, incomplete staining, and broken slides were criteria for exclusion. Histological classification was performed according to the WHO Classification of Breast Tumors [25]. The Research Ethics Committee of the Medical School of the São Paulo State University (UNESP) approved the study.

\section{Immunohistochemical Assay}

Cases were grouped using a conventional tissue microarray (TMA) technique in order to enable maximal standardization of parameters. Considering the use of aged paraffin-embedded tissue, for those at least 5 years old, new sections from the TMA blocks were obtained immediately before the immunohistochemical study, as recommended in the literature $[27,28]$. TMA slides were tested for estrogen receptor (ER), progesterone receptor (PR), HER2, Ki-67, and E-cadherin using the streptavidin-biotin-peroxidase technique. Positive and negative controls were included in each reaction in order to guarantee the reliability of the assays. Antigen retrieval, clone antibodies, dilutions, and suppliers are listed in table 1. Assessments of the molecular phenotype were carried out according to HR expression (HR \pm ), HER2 expression, and proliferative status defined by Ki-67 index (with the cutoff of $20 \%$ accepted by the 13th St Gallen Consensus Conference) [26] into four categories: luminal A (HR+/HER2-/low Ki-67 index), luminal B (HR+/HER2 \pm /high Ki-67 index), HER2 overexpression (HR-/ HER2+), and triple negative (HR-/HER2-). Complete phenotype evaluation was obtained for the included cases. Techniques and analyses were based on updated protocols of the American Society of Clinical Oncology/College of American Pathologists [29, 30]. 
Table 2. Frequencies of the five cytological criteria in 169 FNAC cases classified by molecular phenotype

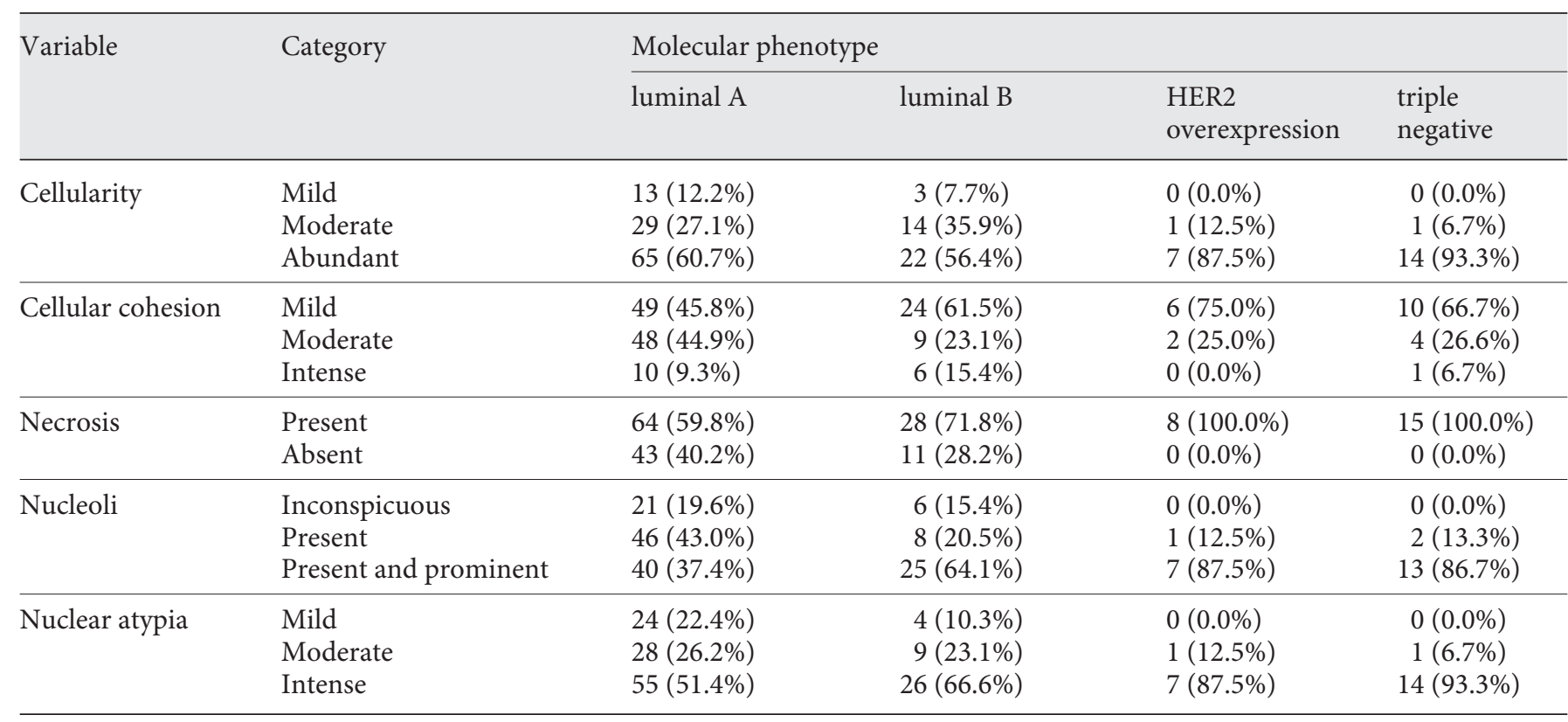

Table 3. Frequencies of markers in TMA performed in 169 cases of invasive breast carcinoma

\begin{tabular}{|c|c|c|c|c|c|c|c|c|c|c|}
\hline \multirow{2}{*}{$\begin{array}{l}\text { Molecular } \\
\text { phenotype }\end{array}$} & \multicolumn{2}{|l|}{ ER } & \multicolumn{2}{|l|}{ PR } & \multicolumn{2}{|l|}{ HER2 } & \multicolumn{2}{|l|}{$\mathrm{Ki}-67^{*}$} & \multicolumn{2}{|l|}{ E-cadherin } \\
\hline & negative & positive & negative & positive & negative & positive & low & high & negative & positive \\
\hline Luminal A & $0(0 \%)$ & $107(63.3 \%)$ & $24(14.2 \%)$ & $83(49.1 \%)$ & $107(63.3 \%)$ & $0(0 \%)$ & $107(63.3 \%)$ & $0(0 \%)$ & $58(34.3 \%)$ & $49(29.0 \%)$ \\
\hline Luminal B & $0(0 \%)$ & $39(23.1 \%)$ & $17(10.1 \%)$ & $22(13.0 \%)$ & $26(15.4 \%)$ & $13(7.7 \%)$ & $3(1.8 \%)$ & $36(21.3 \%)$ & $14(8.3 \%)$ & $25(14.8 \%)$ \\
\hline HER2 overexpression & $8(4.7 \%)$ & $0(0 \%)$ & $8(4.7 \%)$ & $0(0 \%)$ & $0(0 \%)$ & $8(4.7 \%)$ & $3(1.8 \%)$ & $5(3.0 \%)$ & $0(0 \%)$ & $8(4.7 \%)$ \\
\hline Triple negative & $15(8.9 \%)$ & $0(0 \%)$ & $15(8.9 \%)$ & $0(0 \%)$ & $15(8.9 \%)$ & $0(0 \%)$ & $6(3.5 \%)$ & $9(5.3 \%)$ & $0(0 \%)$ & $15(8.9 \%)$ \\
\hline Total & $23(13.6 \%)$ & $146(86.4 \%)$ & $64(37.9 \%)$ & $105(62.1 \%)$ & $148(87.6 \%)$ & $21(12.4 \%)$ & $119(70.4 \%)$ & $50(29.6 \%)$ & $72(42.6 \%)$ & $97(57.4 \%)$ \\
\hline
\end{tabular}

\section{Cytological Criteria}

All cases were analyzed to assess the presence of five individual cytological criteria: cellularity (analyzed at lower magnification as mild, moderate, or abundant); cellular cohesion (the presence of poorly cohesive cells, showing cellular dissociation, was classified as mild cohesion, while the predominance of cell clusters with marked cellular cohesion was classified as moderate and intense cohesion); necrosis (absent or present, i.e. the presence of numerous neutrophils/tumoral diathesis); nucleoli (classified into inconspicuous, present, and prominent), and nuclear atypia (analyzed considering the nuclear:cytoplasmic ratio, i.e. the dimension of nuclei compared with the diameter of red blood cells and features of the nuclear membrane among neoplastic cells, into the categories mild, moderate, and intense).

\section{Statistical Analysis}

SAS for Windows (version 9.2) was used. Data are presented as absolute (n) and relative values (\%) to assess the association of cy- tological criteria with histological type and molecular phenotype. The $\chi^{2}$ test or Fisher's exact test with 95\% CI was used. Values of $\mathrm{p}<0.05$ were considered statistically significant.

\section{Results}

From the total of 297 cases selected for this study, 169 cases were included. After complete immunohistochemical evaluation of the TMA slides, applying the surrogate classification of molecular phenotypes accepted by the 13th St Gallen Consensus Conference [26], the following phenotypes were identified: 107 luminal A (63.3\%), 39 luminal B (23.1\%), 8 HER2 overexpression (4.7\%), and 15 triple negative (8.9\%) (table 2); 146 cases 


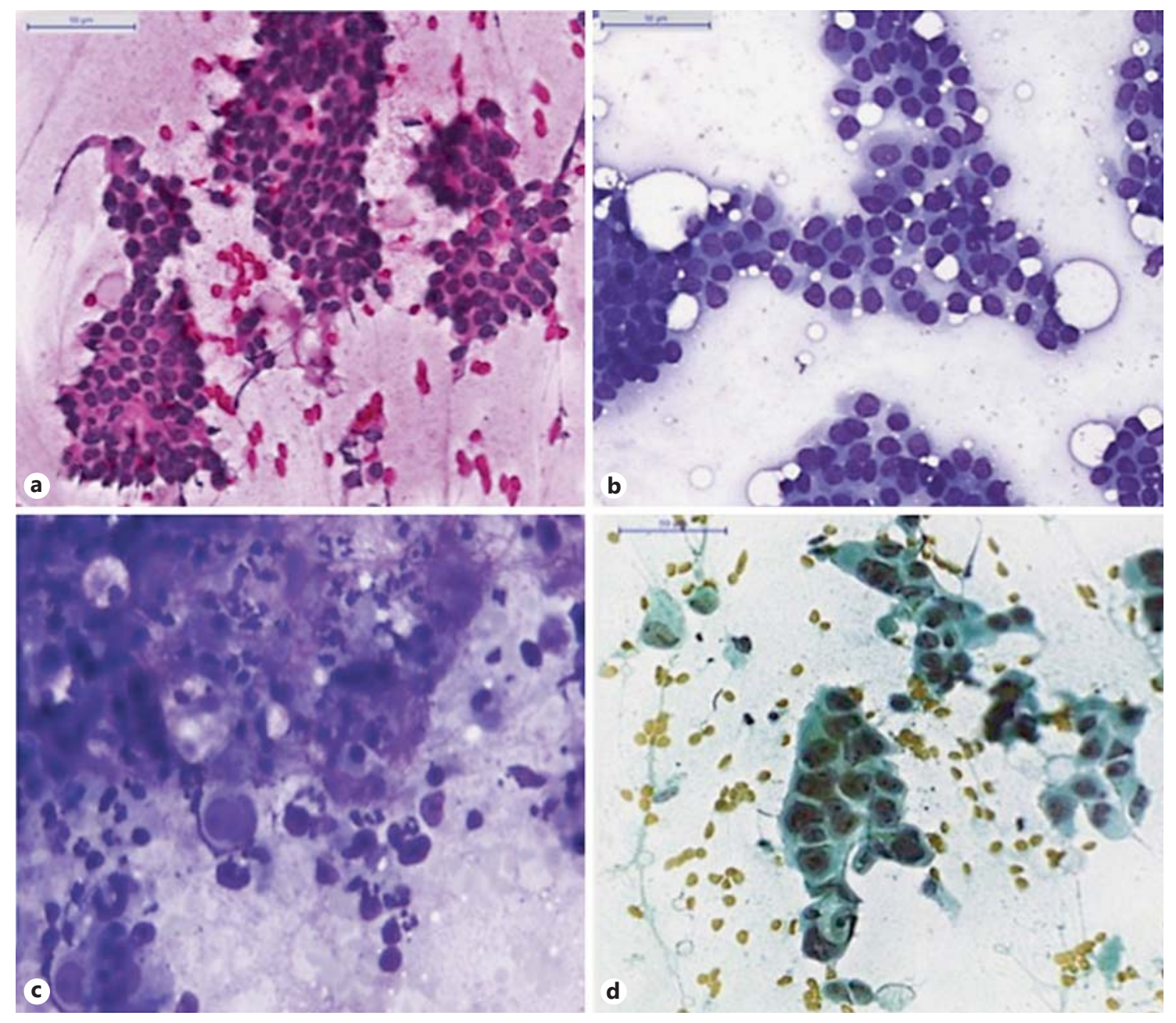

Fig. 1. Cell cohesion (a; HE) and absence of necrosis (b; Giemsa) were mainly associated with the luminal A phenotype in breast FNAC. Presence of necrosis (c; Giemsa), prominent nucleoli, and marked nuclear atypia (d; PAP) were associated with other phenotypes. $\times 400$.

were ER+ $(86.4 \%)$ and classified into the luminal phenotype (table 3 ).

Analysis of frequencies and associations of individual cytological criteria present in FNACs showed that the diagnosis of the luminal phenotype of breast carcinoma was indicated by mild/moderate cellularity $(40.4 \%)$ (OR = 7.12, 95\% CI: 1.61-31.52), inconspicuous, present nucleoli (55.5\%) (OR = 8.31, 95\% CI: 2.36-29.19), and mild/ moderate nuclear atypia $(44.5 \%)(\mathrm{OR}=8.42,95 \% \mathrm{CI}$ : 1.90-37.25).

Inconspicuous, present nucleoli $(62.6 \%)(\mathrm{OR}=4.43$, 95\% CI: 2.24-8.77), moderate or intense cell cohesion (54.2\%) $(\mathrm{OR}=0.46,95 \% \mathrm{CI}: 0.24-0.88)$, and absence of necrosis $(40.2 \%)(\mathrm{OR}=0.32,95 \% \mathrm{CI}: 0.15-0.68)$ were associated mainly with luminal A (fig. 1). The criterion 'nucleoli' also allowed to distinguish luminal A from B $(\mathrm{OR}=2.99,95 \% \mathrm{CI}: 1.39-6.41)$ and showed bordering significance to differentiate luminal B from nonluminal phenotypes $(\mathrm{OR}=3.73$, 95\% CI: 0.94-14.82) (table 4).

\section{Discussion}

Cytological specimens have gained relevance in the era of personalized medicine with the realization of numerous molecular tests - such as DNA extraction techniques, next-generation sequencing, proteomic studies, polymerase chain reaction, and in situ hybridization - made 
Table 4. Association of the five cytological criteria with the molecular phenotypes of breast carcinoma in 169 FNAs of invasive breast carcinoma

\begin{tabular}{|c|c|c|}
\hline Cytological criteria & $\mathrm{p}$ value & OR $(95 \% C I)$ \\
\hline \multicolumn{3}{|l|}{ Cellularity (mild/moderate vs. abundant) } \\
\hline Luminal $\times$ non-luminal & 0.010 & $7.12(1.61-31.52)$ \\
\hline Luminal A $\times$ non-luminal & 0.012 & $6.78(1.51-30.45)$ \\
\hline Luminal $\mathrm{B} \times$ non-luminal & 0.009 & $8.11(1.61-39.49)$ \\
\hline Luminal $\mathrm{A} \times$ luminal $\mathrm{B}$ & 0.637 & $0.84(0.40-1.76)$ \\
\hline Luminal $\mathrm{A} \times$ other (including luminal $\mathrm{B}$ ) & 0.263 & $1.46(0.75-2.84)$ \\
\hline \multicolumn{3}{|l|}{ Cell cohesion (mild vs. moderate/intense) } \\
\hline Luminal $\times$ non-luminal & 0.087 & $0.44(0.17-1.13)$ \\
\hline Luminal A $\times$ non-luminal & 0.043 & $0.37(0.14-0.97)$ \\
\hline Luminal $\mathrm{B} \times$ non-luminal & 0.524 & $0.70(0.23-2.10)$ \\
\hline Luminal $\mathrm{A} \times$ luminal $\mathrm{B}$ & 0.095 & $0.53(0.25-1.12)$ \\
\hline Luminal $\mathrm{A} \times$ other (including luminal $\mathrm{B}$ ) & 0.002 & $0.46(0.24-0.88)$ \\
\hline \multicolumn{3}{|l|}{ Necrosis (present vs. absent) } \\
\hline Luminal $\times$ non-luminal & 0.935 & $0.00(0.00-999.99)$ \\
\hline Luminal A $\times$ non-luminal & 0.934 & $0.00(0.00-999.99)$ \\
\hline Luminal $\mathrm{B} \times$ non-luminal & 0.955 & $0.00(0.00-999.99)$ \\
\hline Luminal A × luminal B & 0.187 & $0.56(0.26-1.30)$ \\
\hline Luminal $\mathrm{A} \times$ other (including luminal $\mathrm{B}$ ) & 0.003 & $0.32(0.15-0.68)$ \\
\hline \multicolumn{3}{|l|}{ Nucleoli (inconspicuous/present vs. prominent) } \\
\hline Luminal $\times$ non-luminal & 0.001 & $8.31(2.36-29.19)$ \\
\hline Luminal $\mathrm{A} \times$ non-luminal & 0.000 & $11.12(3.12-39.94)$ \\
\hline Luminal $\mathrm{B} \times$ non-luminal & 0.061 & $3.73(0.94-14.82)$ \\
\hline Luminal $\mathrm{A} \times$ luminal $\mathrm{B}$ & 0.005 & $2.99(1.39-6.41)$ \\
\hline Luminal $\mathrm{A} \times$ other (including luminal $\mathrm{B}$ ) & 0.000 & $4.43(2.24-8.77)$ \\
\hline \multicolumn{3}{|l|}{ Nuclear atypia (mild/moderate vs. intense) } \\
\hline Luminal $\times$ non-luminal & 0.005 & $8.42(1.90-37.25)$ \\
\hline Luminal A $\times$ non-luminal & 0.003 & $9.93(2.22-44.44)$ \\
\hline Luminal $\mathrm{B} \times$ non-luminal & 0.042 & $5.25(1.06-25.88)$ \\
\hline Luminal $\mathrm{A} \times$ luminal $\mathrm{B}$ & 0.103 & $1.89(0.88-4.07)$ \\
\hline Luminal $\mathrm{A} \times$ other (including luminal $\mathrm{B}$ ) & 0.002 & $2.96(1.48-5.93)$ \\
\hline
\end{tabular}

possible, mainly, by the proper fixation and purity of samples $[16,29,30]$. The cell block is a part of the FNA procedure and enables performing immunocytochemistry and molecular tests for further characterization of breast carcinoma, even posteriorly, as it keeps some properties for future ancillary tests, what can be used especially for research purposes $[27,28]$. Thus, the intrinsic potential of each sample obtained by the FNA procedure is mainly related with the experience of the cytopathologist to bring together a set of diagnostic, predictive, and prognostic data, using systematic analysis, which includes, at first, cytomorphology [16, 31].

Studies in the literature about cytological criteria associated with molecular phenotypes of breast carcinoma in FNAC are limited to the basal phenotype, whose most relevant criterion described was 'necrosis' [20]. To date, no study has been identified that aimed to evaluate which cytological criteria could predict the luminal phenotype of breast carcinoma.

The investigation of five routinely applied cytological criteria in breast FNAC demonstrated that the luminal phenotype has a tendency to present less cellular samples than nonluminal phenotypes, which was equally well evaluated, at low power, for all stains analyzed (Giemsa, PAP, and HE). The presence of cellular aggregates was also observed, and, statistically, mainly for the luminal A phenotype, cellular cohesion was increased compared to other phenotypes.

Decreased cellular cohesion is a significant characteristic associated with an increased risk of malignancy. Wakasa et al. [35] described a cytological subclassification for breast cytology that showed loss of cellular cohesion; for invasive lobular carcinoma, medullary carcinoma, neuroendocrine carcinoma, and solid papillary 
carcinoma, this criterion was present in most cases. However, cellular cohesion was not studied for the luminal phenotype of breast carcinoma yet.

Regarding the criterion 'absence of necrosis', a significant result to distinguish samples of the luminal A phenotype from other phenotypes was also observed. According to the literature, this phenotype presents mostly a lower nuclear grade, so the presence of extensive necrosis is not expected $[8,23]$. For instance, the luminal B phenotype is related to the presence of a higher nuclear grade $[33,34]$, which could require a greater evaluation of nuclear details.

The presence of prominent nucleoli was statistically remarkable for either luminal $\mathrm{B}$ and nonluminal phenotypes compared with the luminal A phenotype. We are aware, however, about the limitations to establish subjective parameters of size for evaluating nucleoli. In this sense, cytomorphometry in computerized images of breast FN aspirates was described as a highly objective tool [36]. Studies using this application technique for identifying specific phenotypes of breast carcinoma are undoubtedly expected.

There is discussion in the literature about preferred staining methods for breast cytology [37, 38]. Giemsa is referred to be associated with fewer technical problems, superior accuracy, sensitivity, and specificity than HE and PAP staining, which, in turn, is especially useful for evaluating nuclear features along with cytoplasmic differentiation $[37,38]$. Comparison of these staining methods was already studied for the evaluation of nodal metastases in breast cancer using intraoperative imprint cytology [37], but it remains an encouraging issue for future studies in the cytomorphology for phenotype prediction purposes.

The differentiation of the luminal phenotype of breast carcinoma, especially the luminal A phenotype, is of clin- ical value, since this phenotype presents a better prognosis and is related to lower mortality and a lower rate of metastasis, but it may be associated with lobular carcinoma according to recent studies $[39,40]$.

\section{Conclusion}

The individual cytological criteria that might indicate the luminal phenotype of breast carcinoma in FNAC were mild-to-moderate cellularity, inconspicuous, present, and nonprominent nucleoli, and mild-to-moderate nuclear atypia. Inconspicuous and nonprominent nucleoli, moderate-to-intense cell cohesion, and absence of necrosis were mainly associated with the luminal A phenotype.

Further research in a larger number of samples, as well as application of new molecular markers possibly related with the luminal phenotype are required to establish which cytological criteria could be predictive and prognostic in breast FNAC. Challenges are considerable, as the luminal phenotype is the most heterogeneous in terms of genetic pathways of growth.

\section{Acknowledgments}

We acknowledge the team of the Amaral Carvalho Hospital, Jaú, Brazil, the team of the Institute of Molecular Pathology and Immunology at the University of Porto (IPATIMUP), and Eloísa Elena Paschoalinotti, who performed the statistical analysis.

\section{Disclosure Statement}

The authors have no conflicts of interest.

\section{References}

1 Kohler BA, Sherman RL, Howlader N, et al: Annual report to the nation on the status of cancer, 1975-2011, featuring incidence of breast cancer subtypes by race/ethnicity, poverty, and state. J Natl Cancer Inst 2015; 107:djv048.

2 Blows FM, Driver KE, Schmidt MK, Broeks A, Van Leeuwen FE, Wesseling J, Cheang MC, Gelmon K, Nielsen TO, Blomqvist C, et al: Subtyping of breast cancer by immunohistochemistry to investigate a relationship between subtype and short and long term survival: a collaborative analysis of data for
10,159 cases from 12 studies. PLoS Med 2010; 7:e1000279.

3 Cancer Genome Atlas Network: Comprehensive molecular portraits of human breast tumours. Nature 2012;490:61-70.

4 Geyer FC, Rodrigues DN, Weigelt B, ReisFilho JS: Molecular classification of estrogen receptor-positive/luminal breast cancers. Adv Anat Pathol 2012;19:39-53.

5 Perou CM, Sørlie T, Eisen MB, Van de Rijn M, Jeffrey SS, Rees CA, et al: Molecular portraits of human breast tumours. Nature 2000;406: 747-752.
6 Sørlie T, Perou CM, Tibshirani R, Aas T, Geisler S, Johnsen H, et al: Gene expression patterns of breast carcinomas distinguish tumor subclasses with clinical implications. Proc Natl Acad Sci USA 2001;98:1086910874.

7 Goldhirsch A, Winer EP, Coates AS, Gelber $\mathrm{RD}$, Piccart-Gebhart $M$, Thürlimann $B$, et al: Personalizing the treatment of women with early breast cancer: highlights of the St Gallen International Expert Consensus on the Primary Therapy of Early Breast Cancer 2013. Ann Oncol 2013;24:2206-2223. 
8 Maisonneuve P, Disalvatore D, Rotmensz N, et al: Proposed new clinicopathological surrogate definitions of luminal A and luminal B (HER2-negative) intrinsic breast cancer subtypes. Breast Cancer Res 2014;16:R65.

9 Coates AS, Winer EP, Goldhirsch A, et al: Tailoring therapies - improving the management of early breast cancer: St. Gallen International Expert Consensus on the Primary Therapy of Early Breast Cancer. Ann Oncol 2015;26:1533-1546.

10 Callagy G, Cattaneo E, Daigo Y, Happerfield L, Bobrow LG, Pharoah PD, Caldas C: Molecular classification of breast carcinomas using tissue microarrays. Diagn Mol Pathol 2003;12:27-34.

11 Martin H, Ellis E: Biopsy by needle puncture and aspiration. Ann Surg 1930;92:169-181.

12 Chaiwun B, Thorner P: Fine needle aspiration for evaluation of breast masses. Curr Opin Obstet and Gynecol 2007;19:48-55.

13 Kocjan G, Feichter G, Hagmar B, et al: Fine needle aspiration cytology: a survey of current European practice. Cytopathology 2006; 17: 219-226.

14 Kocjan G, Bourgain C, Fassina A, et al: The role of breast FNAC in diagnosis and clinical management: a survey of current practice. Cytopathology 2008;19:271-278.

15 Koss LG: The palpable breast nodule: a costeffectiveness analysis of alternate diagnostic approaches. The role of the needle aspiration biopsy. Cancer 1993;72:1499-1502.

16 Collins BT, Garcia TC, Hudson JB: Effective clinical practices for improved FNA biopsy cell block outcomes. Cancer Cytopathol 2015; 123:540-547.

17 Billgren AM, Tani E, Liedberg A, Skoog L, Rutqvist LE: Prognostic significance of tumor cell proliferation analyzed in fine needle aspirates from primary breast cancer. Breast Cancer Res Treat 2002;71:161-170.

18 Löfgren L, Skoog L, Von Schoultz E, Tani E, Isaksson E, Fernstad R, Carlström K, Von Schoultz B: Hormone receptor status in breast cancer - a comparison between surgical specimens and fine needle aspiration biopsies. Cytopathology 2003;14:136-142.

19 Marinšek ZP, Nolde N, Kardum-Skelin I, Nizzoli R, Onal B, Rezanko T, Tani E, Ostović KT, Vielh P, Schmitt F, Kocjan G: Multina- tional study of oestrogen and progesterone receptor immunocytochemistry on breast carcinoma fine needle aspirates. Cytopathology 2013;24:7-20.

20 Dufloth RM, Alves JM, Martins D, et al: Cytological criteria to predict basal phenotype of breast carcinomas. Diagn Cytopathol 2009; 37:809-814.

21 Sikora MJ, Cooper KL, Bahreini A, Luthra S, Wang G, Chandran UR, Davidson NE, Dabbs DJ, Welm AL, Oesterreich S: Invasive lobular carcinoma cell lines are characterized by unique estrogen-mediated gene expression patterns and altered tamoxifen response. Cancer Res 2014;74:1463-1474.

22 Van't Veer LJ, Dai H, Van de Vijver MJ, He YD, Hart AA, Mao M, et al: Gene expression profiling predicts clinical outcome of breast cancer. Nature 2002;415:530-536.

23 Badve S, Dabbs DJ, Schnitt SJ, et al: Basal-like and triple-negative breast cancers: a critical review with an emphasis on the implications for pathologists and oncologists. Mod Pathol 2011;24:157-167.

24 Bose S: Triple-negative breast carcinoma: morphologic and molecular subtypes. Adv Anat Pathol 2015;22:306-313.

25 Lakhani SR, Ellis IO, et al: World Health Organization Classification of Tumours of the Breast, ed 4. Lyon, IARC Press, 2012, pp 34-42.

26 Goldhirsch A, Winer EP, Coates AS, et al: Personalizing the treatment of women with early breast cancer: highlights of the St Gallen International Expert Consensus on the Primary Therapy of Early Breast Cancer 2013. Ann Oncol 2013;24:2206-2223.

27 Mirlacher M, Kasper M, Storz, et al: Influence of slide aging on results of translational research studies using immunohistochemistry. Mod Pathol 2004;17:1414-1420.

28 Nuovo A, Garofalo M, Mikhail A, Nicol AF, Vianna-Andrade C, Nuovo GJ: The effect of aging of formalin-fixed paraffin-embedded tissues on the in situ hybridization and immunohistochemistry signals in cervical lesions. Diagn Mol Pathol 2013;22:164-173.

29 Hammond MEH, Hayes DF, Dowsett M, et al: American Society of Clinical Oncology/College of American Pathologists guideline recommendations for immunohistochemical testing of estrogen and progesterone recep- tors in breast cancer. J Clin Oncol 2010;28: 2784-2795.

30 Wolff A, Hammond ME, Hicks DG, et al: Recommendations for human epidermal growth factor receptor 2 testing in breast cancer: American Society of Clinical Oncology/College of American Pathologists clinical practice guideline update. J Clin Oncol 2013;31:39974013.

31 Knoepp SM, Roh MH: Ancillary techniques on direct-smear aspirate slides: a significant evolution for cytopathology techniques. Cancer Cytopathol 2013;121:120-128.

32 Jain D, Mathur SR, Iyer VK: Cell blocks in cytopathology: a review of preparative methods, utility in diagnosis and role in ancillary studies. Cytopathology 2014;25:356-371.

33 Creighton CJ: The molecular profile of luminal B breast cancer. Biologics 2012;6:289-297.

34 Cheang MC, Chia SK, Voduc D, Gao D, Leung S, Snider J, Watson M, Davies S, Bernard PS, Parker JS, et al: Ki67 index, HER2 status, and prognosis of patients with luminal B breast cancer. J Natl Cancer Inst 2009;101: 736-750.

35 Wakasa T, Nakamura M, Kagiya T, et al: Loss of cellular cohesion in cytology composes a special subgroup of breast tumors - analyses of 37 cases. Acta Cytol 2014;58:89-95.

36 Yadav H, Gill M, Srivastava D, Gupta V, Sen $\mathrm{R}$ : Significance of morphometric parameters in the categorization of breast lesions on cytology. Turk Patoloji Derg 2015;31:188-193.

37 Anand M, Kumar R, Jain P, Asthana S, Deo SV, Shukla NK, Karak A: Comparison of three different staining techniques for intraoperative assessment of nodal metastasis in breast cancer. Diagn Cytopathol 2004;31:423-426.

38 Cibas ES, Ducatman BS: Cytology: Diagnostic Principles and Clinical Correlates, ed 3. Philadelphia, Saunders Elsevier, 2009, pp 221-227.

39 Falck AK, Fernö M, Bendahl PO, Rydén L: St Gallen molecular subtypes in primary breast cancer and matched lymph node metastases aspects on distribution and prognosis for patients with luminal A tumours: results from a prospective randomized trial. BMC Cancer 2013; 13:558.

40 Ciriello G, Gatza ML, Beck AH, et al: Comprehensive molecular portraits of invasive lobular breast cancer. Cell 2015;163:506-519. 